\title{
Polycyclic aromatic hydrocarbon residues in the sediments of a dune lake as a result of power boating
}

\author{
Thorsten D. Mosisch and Angela H. Arthington
}

\section{Abstract}

The potential chemical effects of motorized recreational activities (power boating, water skiing, jet skiing) on Brown Lake, an Australian perched, acid dune lake, were investigated. The objective of this study was to identify and quantify polycyclic aromatic hydrocarbon compounds (PAHs) that may have accumulated in the water and/or the organic bottom sediments of the test lake as a result of the operation of powered recreational watercraft, and to evaluate any risk to aquatic biota. To achieve this, a detailed sampling and analysis programme of the lake water and sediments was implemented. Basic water quality, ionic and nutrient data gave no indication of any deterioration in the water quality of the lake, which was attributable to human usage in general or motorized recreational activities in particular. However, analysis of samples taken from the organic bottom sediments of the lake revealed the presence of $10 \mathrm{PAH}$, including benzo(a)pyrene, chrysene, fluoranthene, phenanthrene and pyrene, which are known to be indicative of fossil fuel combustion processes. Three PAH compounds were found at all survey sites: benzo(a)pyrene (in $46 \%$ of samples), fluoranthene (in 53\% of samples) and pyrene (in $44 \%$ of samples). Results of the analyses were compared with values from published guidelines for residues in freshwaters and sediments, as well as with previous studies dealing with the effects of fossil fuel combustion products on lakes. The highest PAH concentrations in sediments were recorded for benzo(a)pyrene, with three values (830, 955 and $1070 \mu \mathrm{g} \mathrm{kg}^{-1}$ dryweight) exceeding the upper threshold recommended in the draft Canadian freshwater sediment quality guidelines. Benzo(a)pyrene also exceeded the lower Canadian sediment threshold in 51 (40\%) samples. These results indicate a significant level of chemical contamination of Brown Lake as a consequence of four decades of motorized recreational activities and present a significant risk to aquatic biota, particularly benthic and littoral invertebrates associated with the contaminated sediments. 